\title{
Modeling of production and destruction processes in coastal systems on a supercomputer
}

\author{
Alla V. Nikitina ${ }^{2,}$, Ludmila Kravchenko ${ }^{3}$, Ilya Semenov ${ }^{4}$, Yuliya Belova ${ }^{1}$, and Alena \\ Semenyakina ${ }^{4}$ \\ ${ }^{1}$ Don State Technical University, Rostov-on-Don, Russia \\ ${ }^{2}$ Southern Federal University, Rostov-on-Don, Russia \\ ${ }^{3}$ Azov-and-Black Sea engineering institute FSBHEEPT «Donskoy state agrarian university», \\ Zernograd, Russia \\ ${ }^{4}$ Supercomputers and Neurocomputers Research Center, Co. Ltd., Taganrog, Russia
}

\begin{abstract}
The paper covers the development and research mathematical model of production and destruction processes in coastal system, based on the modern information technologies and computational methods to improve the accuracy of predictive modelling the ecological situations in waters during the summer. The model takes into account following: the movement of water flow; microturbulent diffusion; gravitational settling of pollutants; nonlinear interaction of plankton populations; the impact of salinity, temperature, as well as the pollution entrance and deposition from river flows and air. The scheme with weights was proposed for discretization of the developed model, that allowed significantly reduce the error and the computational time. Practical significance of the work is that the proposed model was software implemented; the limits and prospects of its use were defined. On the basis of a supercomputer, the experimental software was designed for mathematical modelling of possible development scenarios of the ecosystems of coastal waters on the example of the Azov Sea in the summer period, taking into account the influence of environment. Parallel implementation was performed using the decomposition methods for computationally labours diffusion-convection problems taking into account the architecture and parameters of multiprocessor computer system.
\end{abstract}

\section{Introduction}

Most of pollutants, emitted by industry and transport, are concentrated in the surface layer of the atmosphere and deposited on the water surface or fall into waters with precipitation. It's known that far from river flows more than $60 \%$ of nutrients, affected on the production and destruction processes of phytoplankton, enter the water from the air (Fig. 1). In this regard, it became necessary to develop mathematical models for prediction changes in the environmental situation in shallow waters and coastal areas, including: the pollution spread

\footnotetext{
* Corresponding author: nikitina.vm@gmail.com
} 
processes in the surface layer of the atmosphere of the coastal zone; the movement of pollutants and sediments, organic deposits, implemented on high-performance computer systems to provide a forecast basis for sustainable development of coastal systems.

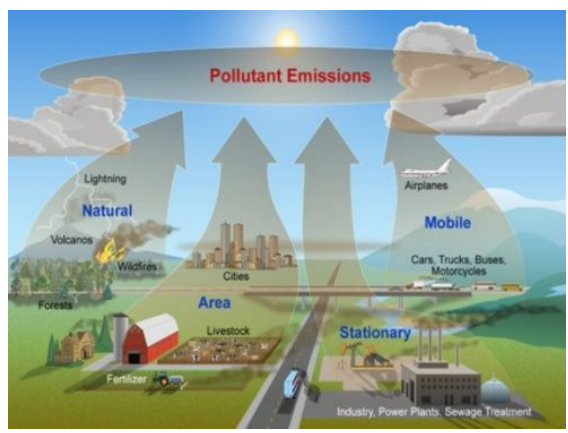

Fig. 1. Pollutant emissions, settling on the surface water layer.

In July 2017, the staff members of the Don State Technical University, the Southern Federal University and the Southern Scientific Center of the Russian Academy of Sciences (RAS) went on an expedition to the Azov Sea aboard the Scientific Research Vessel (SRV) "Deneb" (Fig. 2).
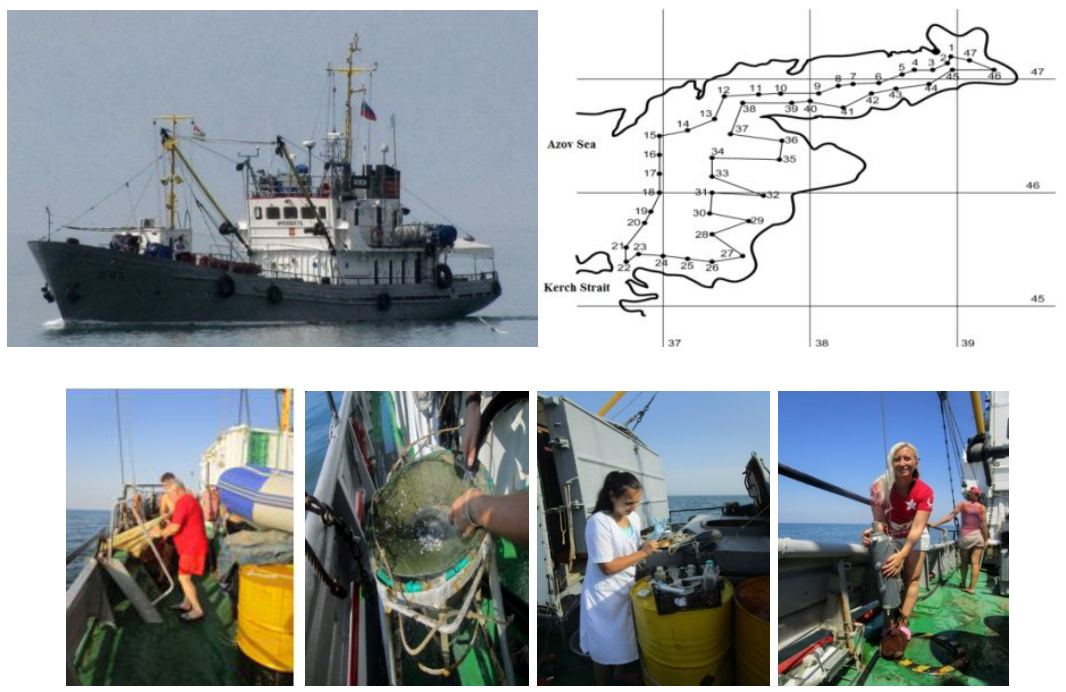

Fig. 2. Expeditionary researches, 2017.

Expedition data, data of the Unified state system of information on the situation in the World ocean ("USIWO") portal, for complex geoinformational analysis of spatial-temporal processes and phenomena, were used for modeling hydrobiological processes in coastal systems (the Azov Sea).

\section{Problem statement}

The model of the production and destruction processes has the form $[1,2]$ :

$$
\frac{\partial q_{i}}{\partial t}+\operatorname{div}\left(\mathbf{U}, q_{i}\right)=\operatorname{div}\left(\mathbf{k}_{i} \operatorname{grad} q_{i}\right)+R_{i}, \mathbf{k}_{i}=\left\{\mu_{i}, \mu_{i}, v_{i}\right\}, i=\overline{1,10}
$$


where $q_{i}$ denotes the concentration of the $i$-th component; $\mathbf{u}$ is the velocity vector of water flow, $\mathbf{u}=\{u, v, w\}, \quad \mathbf{U}=\mathbf{u}+\mathbf{u}_{0 i}$ represents the matter convective transport velocity, $\mathbf{U}=\{U, V, W\} ; \quad \mathbf{u}_{0 i}$ stands for the velocity of the $i$-th component of sedimentation; $R_{i}$ denotes the chemical-biological source, where the index $i$ corresponds to the type thereof: 1-3 are substance concentrations from algae Chlorella vulgaris, Aphanizomenon flos-aquae and Sceletonema costatum; 4 is $\mathrm{PO}_{4} ; 5$ is POP; 6 is DOP; 7 is $\mathrm{NO}_{3} ; 8$ is $\mathrm{NO}_{2}$; 9 is $\mathrm{NH}_{4} ; 10$ is $\mathrm{Si}\left(\mathrm{PO}_{4}\right.$ are phosphates; $\mathrm{POP}$ is suspended organic phosphorus; DOP is dissolved organic phosphorus; $\mathrm{NH}_{4}$ is ammonium; $\mathrm{NO}_{2}$ are nitrites; $\mathrm{NO}_{3}$ are nitrates; $\mathrm{Si}$ is dissolved inorganic silicon); $\mu_{i}, v_{i}$ are diffusion coefficients in horizontal and vertical directions.

It is necessary to add initial conditions:

$$
q_{i}(x, y, z, 0)=q_{i}^{0}(x, y, z),(x, y, z) \in \bar{G}, i=\overline{1,10} .
$$

Let the boundary $\Sigma$ of the cylindrical domain $G$ be sectionally smooth, and suppose that $\Sigma=\Sigma_{H} \cup \Sigma_{o} \cup \sigma$, where $\Sigma_{H}$ is the water bottom surface, $\Sigma_{o}$ is the unperturbed surface of the aquatic medium, and $\sigma$ is the lateral (cylindrical) surface. Let $\mathbf{u}_{n}$ be the normal component of the water flow velocity vector to the $\Sigma$ surface, and let $\mathbf{n}$ be the outer normal vector to the boundary $\Sigma$. Assume that the concentrations $q_{i}$ are:

on the lateral boundary: $q_{i}=0$ if $\mathbf{u}_{n}<0 ; \frac{\partial q_{i}}{\partial \mathbf{n}}=0$ if $\mathbf{u}_{n} \geq 0, i=\overline{1,10}$;

at the bottom: $\frac{\partial q_{i}}{\partial z}=\varepsilon_{1, i} q_{i}, i=\overline{1,3}, \frac{\partial q_{i}}{\partial z}=\varepsilon_{2, i} q_{i}, \quad i=\overline{4,10}$; on $\Sigma_{o}: \frac{\partial q_{i}}{\partial z}=\varphi\left(q_{i}\right), i=\overline{1,10}$,

where $\varphi$ is a given functions; $\varepsilon_{1, i}$ and $\varepsilon_{2, i}$ are nonnegative constants: $\varepsilon_{1, i}, i=\overline{1,3}$, account for the descent of algae to the bottom and their deposition; $\varepsilon_{2, i}, i=\overline{4,10}$ account for absorption of nutrient by bottom sediments.

\subsection{Observational models}

Development of a stochastic model of seasonal biomass variation for each of the main phytoplankton, taking into account the change in the production and destruction rate of organic matter, the change in the concentration of plant pigment (chlorophyll) from water temperature, salinity, oxygen and carbon dioxide, nitrites, nitrates, phosphates, silicon, iron, labile and dissolved organic matter. Active medium reaction of the made it possible to investigate the effect of factors on the growth rate of phytoplankton, while using the combination of principles: the combined effect of Mitcherlich factors and the law of the limiting Liebig factor. The dependences of Benndorf, Mono-Goldani, Romanovskii Yu.M., Bergter, Tyutyunova Yu.V. [3], Tran [4] were researched. According to the productiondestruction ratio of $\mathrm{P} / \mathrm{D}$, one can judge the ability of the aquatic ecosystem to self-purify. If this ratio is close to 1 , then the system produces more organic matter than it can decompose. The conversion coefficient into the organic substance of silicon, nitrogen and phosphorus to natural populations of phytoplankton are determined in accordance with stoichiometry Redfield ratio in atomic terms: $S i: N: P=23: 16: 1$. The phytoplankton algae growth rate is determined by the expressions:

$$
\begin{gathered}
\psi_{i}=K_{N, i} \min \left\{f_{P}\left(q_{4}\right), f_{N}\left(q_{7}, q_{8}, q_{9}\right)\right\}, i=\overline{1,2} ; \\
\psi_{3}=K_{N, 3} \min \left\{f_{P}\left(q_{4}\right), f_{N}\left(q_{7}, q_{8}, q_{9}\right), f_{S i}\left(q_{10}\right)\right\}, K_{N, i}=\varphi_{i}(I) \mu_{i}(T) \eta_{i}(C), \quad i \in\{1,2,3\},
\end{gathered}
$$


where $K_{N, i}, i=\overline{1,3}$ are the maximum specific growth rates of phytoplankton; $I$ is the intensity of illumination; $T$ is the temperature; $C$ is the salinity.

To described the dependence of the nutrient content, let us use the following relations:

$$
f_{P}\left(q_{4}\right)=\frac{q_{4}}{q_{4}+K_{4}} ; f_{S i}\left(q_{10}\right)=\frac{q_{10}}{q_{10}+K_{10}}, f_{N}\left(q_{7}, q_{8}, q_{9}\right)=\frac{\left(q_{7}+q_{8}\right) \exp \left(-K_{p s i} q_{9}\right)}{K_{7}+\left(q_{7}+q_{8}\right)}+\frac{q_{9}}{K_{9}+q_{9}},
$$

where $K_{4}, K_{7}, K_{9}, K_{10}$ stand, respectively, for the phosphate, nitrate, ammonium and silicon half-saturation constant, $K_{p s i}$ is the ammonium inhibition ratio.

Natural measurements for modeling the production and destruction processes of phytoplankton in the Azov Sea are presented in the Table 1.

Table 1. Data of natural measurements.

\begin{tabular}{|c|c|c|c|c|c|}
\hline Species name & $\begin{array}{c}\text { Number of } \\
\text { station }\end{array}$ & $\begin{array}{c}\text { Quantity, thousand } \\
\text { cells } / 1\end{array}$ & $\mathrm{~T},{ }^{\circ} \mathrm{C}$ & $\mathrm{T}_{\mathrm{opt}},{ }^{\circ} \mathrm{C}$ & $\mathrm{S}_{\mathrm{opt},} \%$ \\
\hline \multirow{2}{*}{$\begin{array}{l}\text { Chlorella } \\
\text { vulgaris }\end{array}$} & 42 & 6500 & \multirow{2}{*}{24.8} & \multirow{2}{*}{$26-36$} & \multirow{2}{*}{$10-12$} \\
\hline & 44 & 3200 & & & \\
\hline \multirow{3}{*}{$\begin{array}{l}\text { Aphanizomenon } \\
\text { flos-aquae }\end{array}$} & 42 & 100 & 24.8 & \multirow{3}{*}{$24-26$} & \multirow{3}{*}{10} \\
\hline & 44 & 400 & 24.2 & & \\
\hline & 44 & 200 & 24.2 & & \\
\hline \multirow{5}{*}{$\begin{array}{l}\text { Sceletonema } \\
\text { costatum }\end{array}$} & 16 & 200 & 27 & \multirow{5}{*}{$2-8$} & \multirow{5}{*}{$10.5-13.2$} \\
\hline & 33 & 60 & 27.4 & & \\
\hline & 35 & 780 & 26.5 & & \\
\hline & 35 & 1730 & 26.5 & & \\
\hline & 39 & 1000 & 25.7 & & \\
\hline
\end{tabular}

The different dependences, used in the observational models to account for the effects of salinity, temperature and illumination on the productivity function of phytoplankton in the coastal system are presented in the Table 2 .

Table 2. Functional forms of phytoplankton productivity.

\begin{tabular}{|c|c|c|}
\hline Name & Expression & Source \\
\hline $\begin{array}{l}\text { Krog and } \\
\text { Shelford }\end{array}$ & $\eta_{i}(C)=\eta_{0} \exp \left[-\left\{\left(C-C_{o p t}\right) / \sigma_{c}\right\}^{2}-\eta_{1} C+\eta_{2}\right], i \in\{1,2,3\}$ & $\begin{array}{l}\text { Shelford, 1913, } \\
\text { Vinberg, 1966, } \\
\text { Dombrowski, } \\
1990\end{array}$ \\
\hline Eppley & $\begin{array}{l}\mu_{i}(T)=\mu_{0} \exp \left(r_{\mu} T(z)\right), \mu_{0} \text { is the specific growth rate at } 0^{\circ} \mathrm{C}, \\
T(z) \text { is the water temperature at a depth of } z\end{array}$ & Eppley, 1972 \\
\hline Sidko & $\varphi_{i}(I)=\left(b I+c^{2}\right)^{1 / 2}-a I-c$ & $\begin{array}{l}\text { Sidko, et al., } \\
1975\end{array}$ \\
\hline Belyanin & $\varphi_{i}(I)=\varphi_{0}(1-\exp (-I / b)) /(1-a I)$ & $\begin{array}{l}\text { Belyanin, et. al., } \\
1980\end{array}$ \\
\hline Dombrowski & $\mu_{i}(T)=\mu_{0} \exp \left[-\left\{\left(T-T_{o p t}\right) / \sigma_{T}\right\}^{2}-\mu_{1} T+\mu_{2}\right]$ & $\begin{array}{l}\text { Dombrowski, } \\
\text { et. al., } 1990\end{array}$ \\
\hline $\begin{array}{l}\text { Yakushev- } \\
\text { Mikhailovsky }\end{array}$ & $\psi_{i}=\psi_{\max } a \varphi_{i}(I) \min \left(q_{i}\left(q_{4}, q_{7}, q_{8}, q_{9}\right)\right)$ & $\begin{array}{l}\text { Yakushev, } \\
\text { Mikhailovsky, } \\
1993\end{array}$ \\
\hline Inkal & $\psi=\psi_{\max } q_{i}\left(q_{7,} q_{8}, q_{9}\right) \varphi_{i}(I) \mu_{i}(T)$ & $\begin{array}{l}\text { Inkal, et al., } \\
1997\end{array}$ \\
\hline Gin & $\mu_{i}(T)=\exp \left(k_{t} T\right), k_{t}$ is the temperature coefficient & Gin, et al., 1998 \\
\hline Fennell & $\begin{array}{l}\varphi_{i}(I) \mu_{i}(T)=\alpha_{0} \exp (a T)\left(I / I_{o p t}\right) \exp \left(1-I / I_{\text {opt }}\right), \alpha_{0} \text { is the } \\
\text { growth rate of phytoplankton at } 0^{\circ} \mathrm{C}(0.8), a=0.063\end{array}$ & Fennell, 1999 \\
\hline
\end{tabular}




\section{Results of experimental researches}

The grid equations were obtained as a result of finite-difference approximations of problem (1) - (3) using a scheme with weights [5]. A modified alternating triangular method (MATM) [7-10] and the domain decomposition by the $k$-means algorithm (Fig.3) were used for the solution of the problem (1) - (3).

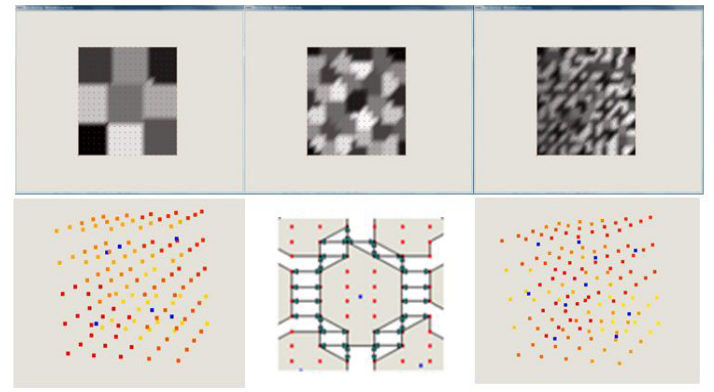

Fig. 3. Results of the $k$-means method for model domain decomposition into $9,38,150$ subdomains (for a two-dimensional domain); into 6 and 10 subdomains (for a three-dimensional domain).

The estimation for comparing the efficiency values of standard and developed algorithms has the form:

$$
\delta=\sqrt{\sum_{k=1}^{n}\left(E_{k}-E_{(s t) k}\right)^{2}} / \sqrt{\sum_{k=1}^{n} E_{k}^{2}} .
$$

where $E, E_{(s t)}$ are the efficiency of the developed and standard algorithms, respectively.

We obtained that the efficiency increases on 10 to $20 \%$ using the developed algorithm (based on the $k$-means method) for solving problem (1) - (3).

A software complex (SC) was developed for solving the problem (1) - (3). Numerical experiments were performed for modeling hydrochemical conditions of coastal systems in the summer, taking into account the influence of the environment. The results are shown in Figs. 4-6. The influence of the Azov Sea water flow structures on the distribution of phytoplankton concentration is shown in Fig. 4 (the concentration Chlorella vulgaris $\left(q_{1}\right)$ is indicated by the black color; the concentration of Aphanizomenon flos-aquae $\left(q_{2}\right)$ - by the white color).
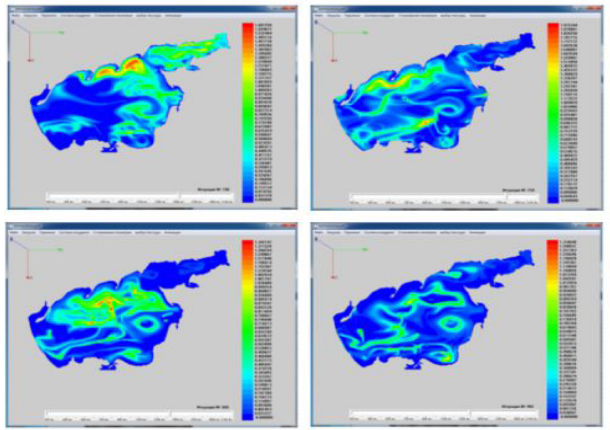

Fig. 4. Distribution of phytoplankton $q_{2}$

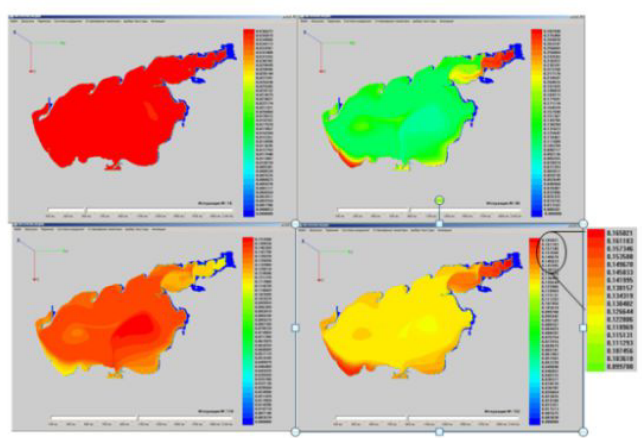

Fig. 5. Distribution of nitrates concentration $q_{7}$ 
Calculation results of biogenic substance (nitrates) concentrations based on model (1) (3) (initial distribution of water flow fields for the northern wind) are given in Fig. 5. Joint distribution of green and blue-green algae concentrations in the summer is shown in Fig. 6.

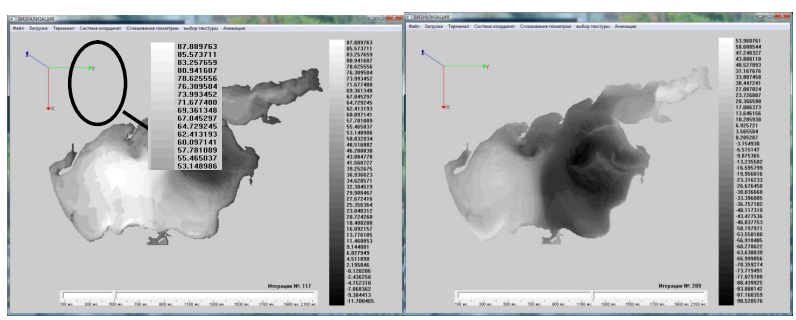

Fig. 6. Joint distribution of algae concentrations.

Actual data from the "USIWO" portal (see Fig. 7A) and satellite data from the SRC "Planeta" [11], shown in Fig. 7B (phytoplankton spots are visible, revealing the structure of currents), were used for verification of the model (1) - (3) and validation of the adequacy of the SC [12]. The results of satellite monitoring of the Earth are used in this paper to control the quality modeling of processes of hydrodynamics and biological kinetics. The satellite monitoring data of the Azov Sea, obtained by SRC "Planeta", are given in Fig. 8.

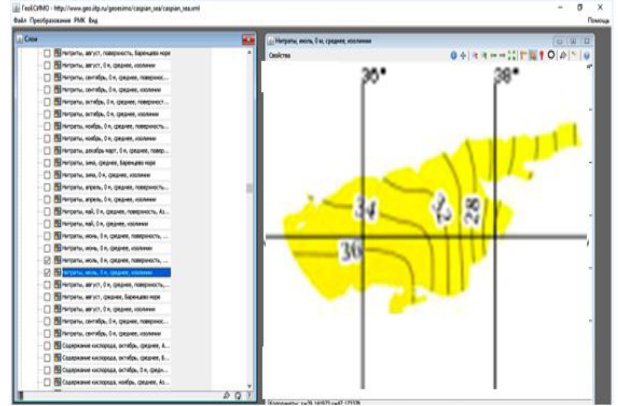

A)

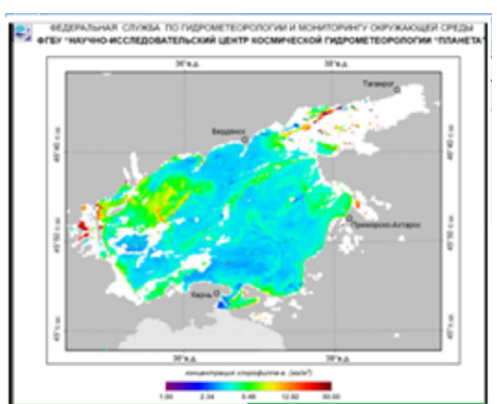

B)

Fig.7. A) Ecological data from the "USIWO" portal; B) Satellite image of the Azov Sea by the SRC "Planeta".

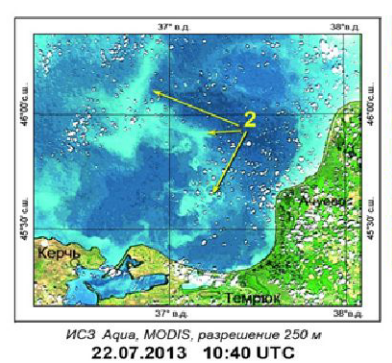

A)

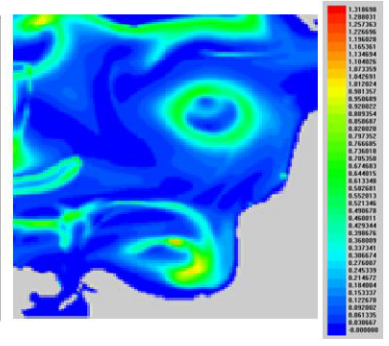

B)

Fig. 8. Comparison of the software complex results with the satellite data. A: satellite photo of the Azov Sea by RC "Planeta"; B: the software complex result (the variation of the phytoplankton concentration)

\section{Conclusion}

Stochiometric ratios of nutrients for different phytoplankton species were researched. These ratios allow for the determination of a limiting substance. Also, observational models 
describing the production and destruction processes were considered. We developed a three-dimensional mathematical model of transformation of phosphorus, nitrogen and silicon forms in the multi-species phytoplankton evolution problem for coastal systems. The numerical implementation of the model was carried out on a multiprocessor computer system with distributed memory. We obtained theoretical estimates for the accelerations and efficiency of parallel algorithms. Due to the algorithm based on the $k$-means method the efficiency at solving the problem was increased. An analysis of similar SCs was carried out. The overall result is that the prediction accuracy of changes in pollutants and plankton concentrations in shallow waters increased by 10 to $20 \%$, depending on the model problem of biological kinetics.

This paper was partially supported by the grant No.17-11-01286 of the Russian Science Foundation.

\section{References}

1. G.G. Matishov, V.G. Ilyichev, V.L. Semin, V.V. Kulygin, Doc. Academy of Sciences, 420, 282 (2008)

2. E.V. Yakushev, G.E. Mikhailovsky, Air-Water Gas Transfer, Sel. Papers, Third Int. Symp., Heidelberg University, ed. by B. Jaehne and E.C. Monahan, 37 (1995)

3. Yu. Tyutyunov, I. Senina, R. Arditi, The American Naturalist, 164, 722 (2004)

4. J.K. Trân, Verh. Internat. Verein. Limnol, 30, 2, 302 (2008)

5. A.I. Sukhinov, A.E. Chistyakov, A.A. Semenyakina, A.V. Nikitina, Computer researches and modeling, 8, 1, 151 (2016)

6. A.A. Samarskiy, Theory of difference schemes (Nauka, Moscow, 1989)

7. A.N. Konovalov, Siberian mathematical journal, 43, 3, 552 (2002)

8. B. Chetverushkin, V. Gasilov, M. Iakobovski, S. Polyakov, E. Kartasheva, A. Boldarev, I. Abalakin, A. Minkin, Parallel Computational Fluid Dynamics, 501 (2005)

9. A.I. Sukhinov, A.E. Chistyakov, Mathematical Models and Computer Simulations, 24, 1, 3 (2012)

10. V.V. Sidoryakina, A.I. Sukhinov, J. Computational Mathematics and Mathematical Physics, 57, 6, 978 (2017)

11. State Research Center "Planeta", http://planet.iitp.ru/english/index_eng.htm

12. A.V. Nikitina, A.I. Sukhinov, G.A. Ougolnitsky, A.B. Usov, A.E. Chistyakov, M.V. Puchkin, I.S. Semenov, Mathematical Models and Computer Simulations, 28, 7, $96(2016)$ 